\title{
A Tunable and Program-Erasable Capacitor on Si with Excellent Tuning Memory
}

\author{
C. H. Lai ${ }^{\mathrm{a}}$, C. F. Lee ${ }^{\mathrm{a}}$, Albert Chin ${ }^{\mathrm{a}}$, C. Zhu' ${ }^{\mathrm{b}}$, M..F. Li ${ }^{\mathrm{b}}$, S. P. McAlister ${ }^{\mathrm{c}}$, and D. L. Kwong ${ }^{\mathrm{d}}$ \\ ${ }^{a}$ Dept. of Electronics Eng., National Chiao Tung Univ., Hsinchu, Taiwan \\ ${ }^{b}$ Silicon Nano Device Lab, Dept. of Electrical and Computer Engineering, National Univ. of Singapore, \\ Singapore, 119260 \\ ${ }^{c}$ National Research Council of Canada, Ottawa, Canada \\ ${ }^{\mathrm{d}}$ Dept. of Electrical \& Computer Eng., The Univ. of Texas, Austin, TX 78752, USA
}

\begin{abstract}
A novel tunable and program-erasable high-k AIN MIS capacitor is demonstrated for the first time with excellent tuning memory, which is useful to tune the impedance mismatching and resonance frequency without always connected voltage bias circuit. Large $C_{\max } / C_{\min }$ tunability of 12 is obtained due to the high-K AIN dielectric with high $5 \mu \mathrm{F} / \mathrm{\mu m}^{2}$ capacitance density. Good tuning memory is evidenced from the small $V_{\text {th }}$ variation after program or erase at $+4 \mathrm{~V}$ or $-4 \mathrm{~V}$ for $10,000 \mathrm{~s}$ and the potential of years long extrapolated memory time.
\end{abstract}

\section{INTRODUCTION}

Since the development of RF lCs, it is highly desirable to have the tuning capability inside the RF circuit. This is because the variations of process and device modeling always shift the resonance frequency of LC tank, create impedance mismatch and change the bandpass frequency from circuit simulation. The tuning capability may from the changing $\mathrm{L}$ or $\mathrm{C}$ value inside the circuit, but the changing $\mathrm{L}$ is still under development even using MEMS technology. In contrast, the tunable capacitor, or varactor is already used to tune the resonance frequency of $\mathrm{VCO}$, but additional voltage bias circuit must be used. In this paper, we propose and demonstrate a new tunable high- $\kappa$ capacitor [1]-[2] like the varactor [3]-[4], but have additional function of long program-erase retention and capable to memorize the tuned capacitor value without always connected voltage bias circuit. Fig. 1 shows the application of this non-volatile capacitor. The mechanism of this novel program-erasable capacitor is due to the injected carriers trapping and de-trapping inside the AIN capacitor and shifts the $\mathrm{C}-\mathrm{V}$ curve permanently. Similar charge trapping idea has successfully applied to form semi-insulating $\mathrm{Si}$ for $\mathrm{RF}$ passive devices with performance close to those on GaAs [5]-[6]. The trapped charges can only be removed by the applied erase voltage and shift the $\mathrm{C}-\mathrm{V}$ back. Although the program and erase function is similar to non-volatile Si/oxide/nitride/oxide/Si (SONOS) memory [7], the mechanism is quite different since only single trapping AIN layer is used rather than the complicated SONOS structure [7]. In addition, the capacitance density of single layer high- $\mathrm{K}$ AlN capacitor is also much higher than the SONOS and close to the high-K $\mathrm{Al}_{2} \mathrm{O}_{3}$ capacitor [1], which is important to reduce the capacitor area and die size of RF ICs. This simple varactor with program-erasable function and long tuning memory capability should find wide applications to tune the impedance mismatching and resonance frequency offset without using always connected voltage bias circuit and with increasing the successful rate of RF IC design with fewer turn around runs.

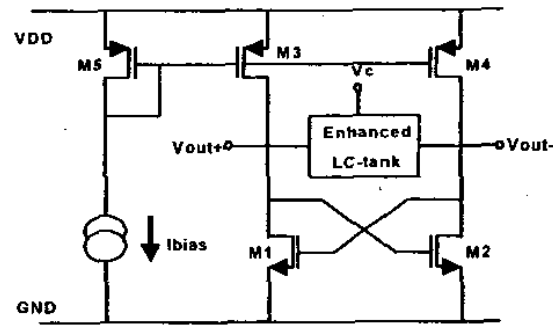

(a)

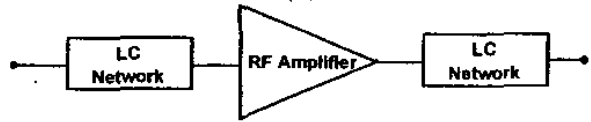

(b)

Fig. 1. The application of program-erasable high-א tunable capacitor for (a) VCO and (b) RF amplifter. The tuning memory of this device can greatly simply the VCO without external voltage bias circuit and reduce the turn around time due to impedance mismatch in $\mathrm{V} / \mathrm{O}$ LC networks of RF amplifier.

\section{EXPERIMENTAL PROCEDURE}

The MIS capacitors were fabricated using advanced high-K dielectric process [1]-[2]. The device layout is similar to varactor used in RF circuit, where the $\mathrm{n}^{+}$sourcedrain is used to connect the bottom of MIS capacitors. After defining and opening the active capacitor area, a thin AIN layer was deposited on $\mathrm{Si}$, and then annealed at $400^{\circ} \mathrm{C}$ to form the high-K AIN dielectric. Finally, both the 
top capacitor electrode and transmission line was defined with patterned $\mathrm{Al}$. The high-K MIM capacitors were characterized using an HP4284A precision LCR meter to $1 \mathrm{MHz}$ for tuning capability measurement. The Sparameters were measured to $20 \mathrm{GHz}$ to characterize the $\mathrm{RF}$ performance using an HP8510C network analyzer. Additional 'through' transmission lines [5] were measured to de-embed the parasitic inductance in the RF layout of the MIM capacitor. A similar method was used for RF noise analysis in 0.18 to $0.13 \mu \mathrm{m}$ MOSFETs [8].

\section{RESULTS AND DISCUSSION}

\section{A. Tuning and program-erase performance:}

Fig. 2 shows the measured C-V characteristics of the novel high- $\kappa$ MIS tunable capacitor. The extremely large tunability of 12 in $\mathrm{C}_{\max } / \mathrm{C}_{\min }$ is due to the high capacitance density $\left(\varepsilon_{0} k / t_{k}\right)$ using high- $\kappa$ gate dielectric. The achieved capacitance density of $4.8 \mathrm{fF} / \mu^{2}$ is close to that of high- $K$ $\mathrm{Al}_{2} \mathrm{O}_{3} \mathrm{MIM}$ capacitor reported previously [1]. In additional to the large tunability, this high-K MIS capacitor has unique program and erase functions that can shift the flat band voltage $\left(\mathrm{V}_{\mathrm{FB}}\right)$ of capacitance by applied $+V_{g}$ and $-V_{g}$, respectively. It is important to notice that such program-erase function is impossible in high- $\mathrm{K}_{2} \mathrm{O}_{3}$ MIS capacitor as shown in Fig. 3, where continuously increasing the $V_{F B}$ is found regardless applying $-V_{g}$.

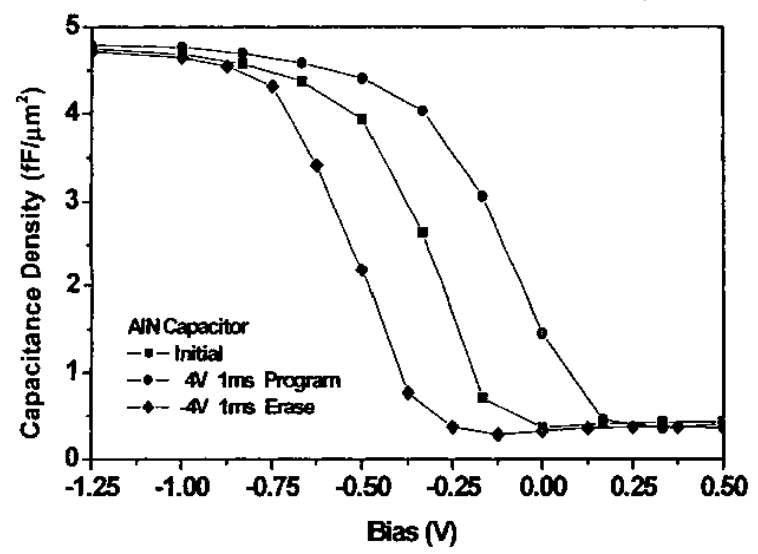

Fig. 2. The measured $\mathrm{C}-\mathrm{V}$ characteristics of high-K AIN MIS capacitor. Very large tuning range can be obtained due to the high density capacitors using high- $\kappa$ gate dielectric. The shift of $V_{F B}$ in $C-V$ curves is achieved by $+V_{g}$ and $-V_{g}$ for applied program and erase voltage, respectively.

The reason is because the electron can be injected and trapped into the large energy bandgap $\left(E_{G}\right)$ insulating $\mathrm{Al}_{2} \mathrm{O}_{3}$ during both $+\mathrm{V}_{\mathrm{g}}$ and $-\mathrm{V}_{\mathrm{g}}$ bias that causes continuously increasing the $\mathrm{V}_{\mathrm{FB}}$. In contrast, the hole may also be injected into the AIN MIS capacitor during $-\mathrm{V}_{\mathrm{g}}$ bias to cause the stored charge decrease because of the relatively smaller $E_{G}$ in wide bandgap semiconductor $A \mathbb{N}$ $(\sim 5.0 \mathrm{eV})$. To the best of our knowledge, this is the first report that the single layer high- $\kappa$ dielectric can have the program-erase function.

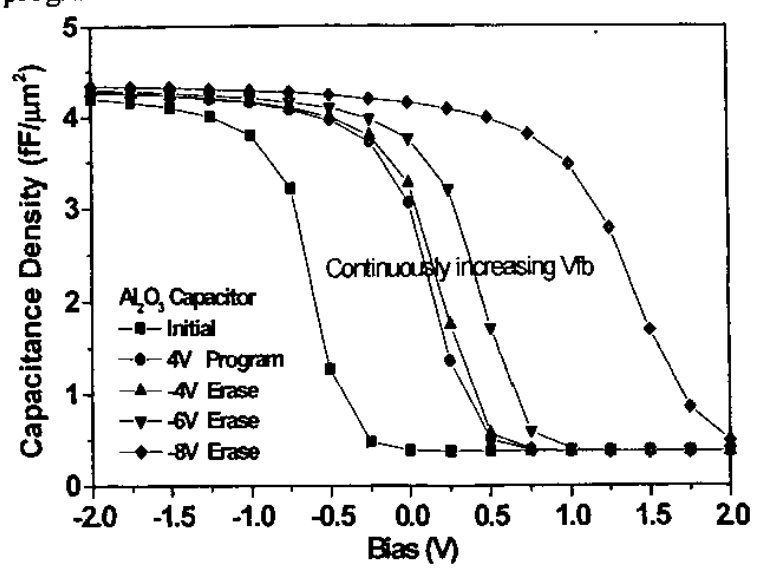

Fig. 3. The measured $\mathrm{C}-\mathrm{V}$ characteristics of high-K $\mathrm{Al}_{2} \mathrm{O}_{3}$ MIS capacitor. Although similar large tenability is achieved using the high- $\mathrm{K} \mathrm{Al}_{2} \mathrm{O}_{3}$ gate dielectric, the shift of $\mathrm{C}-\mathrm{V}$ can not be restored even at $-\mathrm{V}_{\mathrm{g}}$ bias of $-8 \mathrm{~V}$. The continuous increasing $\mathrm{V}_{\mathrm{FB}}$ during $\mathrm{V}_{\mathrm{g}}$ bias is due to the electron injection from gate electrode into the trap states in the $\mathrm{Al}_{2} \mathrm{O}_{3}$ MIS capacitor.

\section{B. Program-erase retention characteristics:}

It is important that long retention of shifted $\mathrm{C}-\mathrm{V}$ must be preserved after removing the applied voltage. Fig. 4 shows the measured $\mathrm{C}-\mathrm{V}$ characteristics of AIN MIS capacitor after applying respective program or erase voltage of $+4 \mathrm{~V}$ or $-4 \mathrm{~V}$ for $1 \mathrm{~ms}$. The $\mathrm{C}-\mathrm{V}$ measurements were done after the program-erase from $10 \mathrm{~s}$ to $10,000 \mathrm{~s}$. Good program-erase retention is evidenced from the small shift of $\mathrm{C}-\mathrm{V}$ characteristics or $\mathrm{V}_{\mathrm{FB}}$ even after removing the write voltage for $10,000 \mathrm{~s}$.

To further evaluate the program-erase retention, we have plotted the threshold voltage $\left(\mathrm{V}_{\mathrm{th}}\right)$ from the measured $\mathrm{C}-\mathrm{V}$ curves as a function of time. Fig. 5 shows the $\mathrm{V}_{\mathrm{th}}$ and retention time plot. The almost symmetrical $+V_{\text {th }}$ for program and $-V_{\text {th }}$ for erase is important for low voltage application. The small variation in $\pm V_{t h}$ with time suggests the excellent memory characteristics and may be useful for years long retention after removing the program-erase voltage similar to non-volatile memory. 


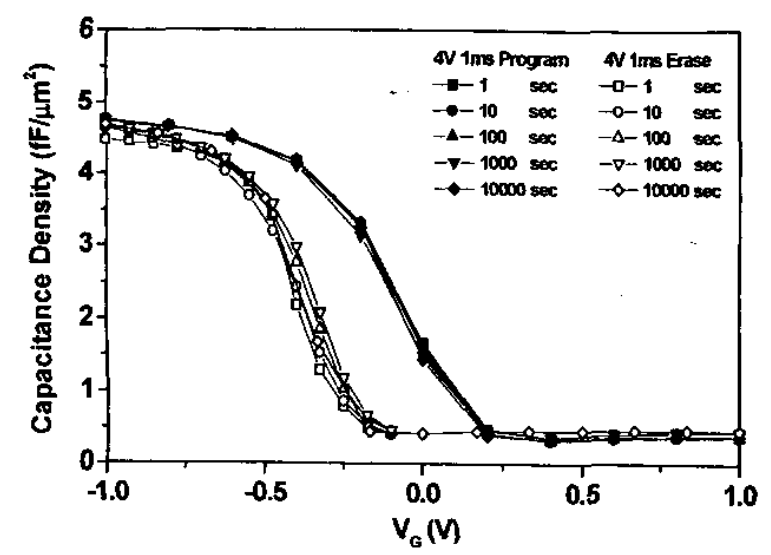

Fig. 4. The measured C-V characteristics of AIN MIS capacitor after program at $+4 \mathrm{~V}$ or erase at $-4 \mathrm{~V}$ for $1 \mathrm{~ms}$. The retention property is obtained by measuring the $\mathrm{C}-\mathrm{V}$ after removing the program or erase voltage for $10 \mathrm{~s}$ to $10,000 \mathrm{~s}$.

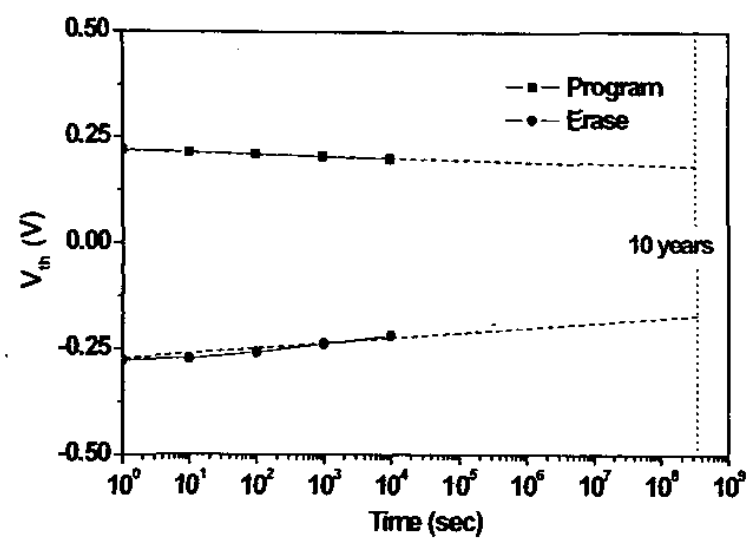

Fig. 5. The retention characteristics of $+V_{t h}$ and $-V_{\text {th }}$ from $C-V$ curves in Fig. 4 of AlN MIS capacitor programmed or erased at $+4 \mathrm{~V}$ or $-4 \mathrm{~V}$ for $1 \mathrm{~ms}$. Excellent memory characteristics can be evidenced from the small $V_{\text {th }}$ variation and extrapolated years long memory time.

\section{RF characteristics:}

To investigate the RF characteristics of this tunable and program-erasable AIN capacitor, we have first established the equivalent circuit model. As shown in Fig. 6 , the parallel $C$ and $R_{p}$ are the basic models for high-K capacitor, whereas additional small series $R_{s}$ and $L_{s}$ are the parasitic resistance and inductance in the coplanar transmission line. The $R$ and $C$ shunt pass to ground is the transmission line loss to the ground [5]. The intrinsic RF characteristics of AIN MIS capacitor can be further obtained by de-embedding the through line [8]-[9] in additional to the open pad.

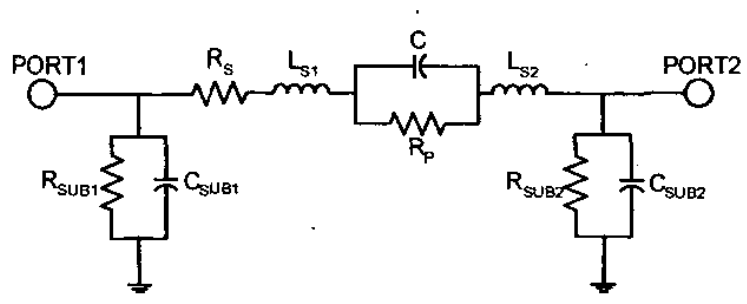

Fig. 6. The equivalent circuit model for AIN capacitor simulation at $\mathrm{RF}$ regime.

Fig. 7 illustrates the measured S-parameters for AIN MIS capacitors. For comparison, the simulated results using equivalent circuit model in Fig. 6 are also shown in these figures. The good agreement between measured and simulated data over the wide frequency range from 200 $\mathrm{MHz}$ to $20 \mathrm{GHz}$ suggests that the equivalent circuit model shown in Fig. 6 is suitable and reliable for capacitor extraction.

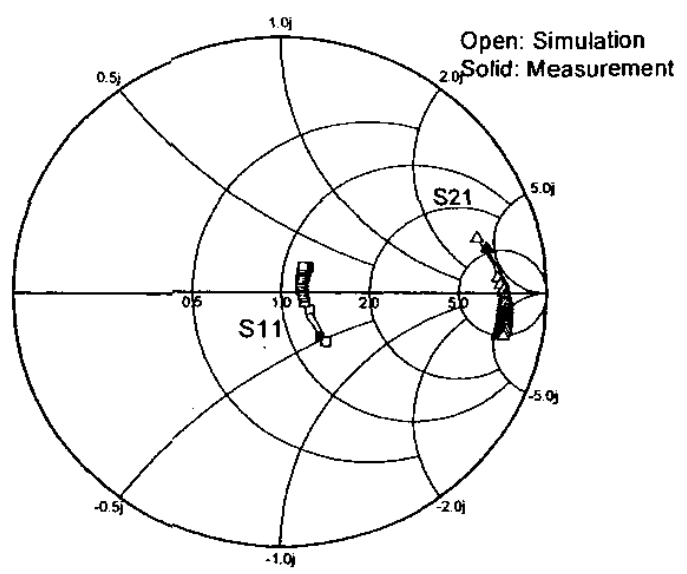

Fig. 7. The measured and simulated S-parameters of programerasable AIN capacitors.

We have further plotted the extracted capacitance from the measured and simulated S-parameters. Fig. 8 is the frequency dependence on capacitance for AIN MIS capacitors. High capacitance value can be maintained until the frequency approaching a resonance frequency of 9.7 $\mathrm{GHz}$, which is due to the small parasitic inductance in the transmission line even after de-embedding. The relatively low resonance frequency is also due to the large capacitance and high-K dielectric property of AIN. 


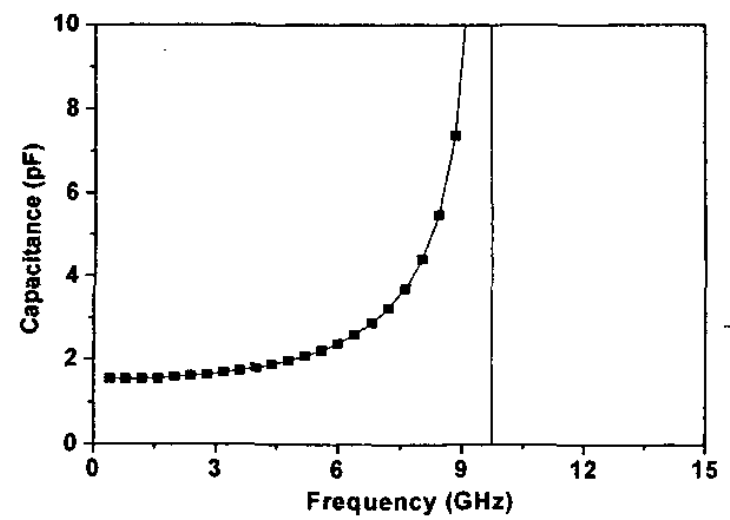

Fig. 8. The frequency-dependent capacitance for programerasable AIN MIS capacitors.

We have also plotted the important Q-factor. Fig. 9 shows the Q-factor for memorable AIN MIM capacitors. Good RF performance can be evidenced from the high Qfactor of 70 at high frequency of $6 \mathrm{GHz}$. The Q-factor decreases rapidly as frequency approaching to resonance frequency and dominated by parasitic inductance from transmission line.

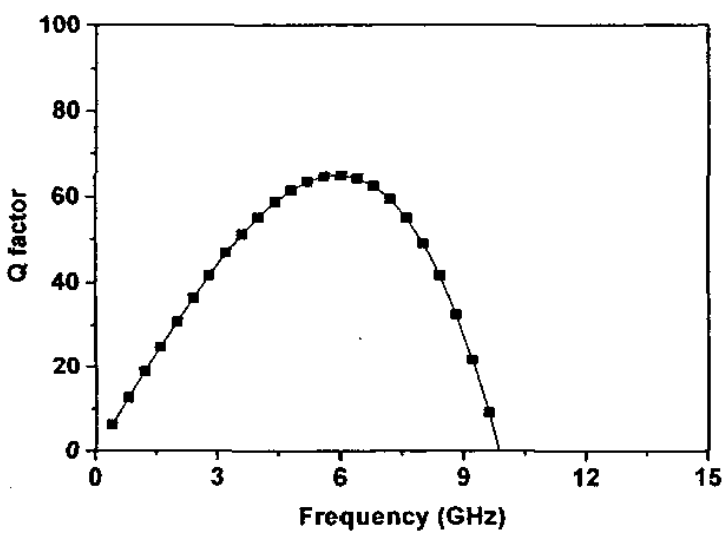

Fig. 9. The Q-factor of the $4.8 \mathrm{fF} / \mu \mathrm{m}^{2}$ AlN MIS capacitors as a function of frequency. Large Q-factor of 70 is obtained.

\section{CONCLUSION}

We have developed a novel program-erasable high- $\kappa$ AIN MIS capacitor with long tuning memory. High capacitance density of $5 \mu \mathrm{F} / \mu \mathrm{m}^{2}$ is obtained with large $\mathrm{C}_{\max } / \mathrm{C}_{\min }$ tunability of 12 . Good tuning memory is evidenced from the small $V_{\text {th }}$ variation after program or erase at $\pm 4 \mathrm{~V}$ for $10,000 \mathrm{~s}$ and potential of years long extrapolated memory time.

\section{ACKNOWLEDGEMENT}

The authors would like to thank Dr. G. W. Huang at National Nano Devices Lab (NDL) for their help in the measurement.

\section{REFERENCES}

[1] S. B. Chen, C. H. Lai, A. Chin, J. C. Hsieh, and J. Liu, "RF $\mathrm{MIM}$ capacitors using high- $\mathrm{K}_{2} \mathrm{I}_{2} \mathrm{O}_{3}$ and $\mathrm{AITiO}_{\mathrm{x}}$ dielectrics," in IEEE MTT-S International Microwave Symp. Dig., vol. 1, pp. 201-204, 2002.

[2] C. H. Huang, M.Y. Yang, A. Chin, C. X. Zhu, M. F. Li, and D. L. Kwong, "High density RF MIM capacitors using high- $\square$ AlTaO ${ }_{x}$ dielectrics," in IEEE MTT-S International Microwave Symp. Dig., vol. 1, pp. 507-510, 2003.

[3] D. Coolbaugh, E. Eshun, R. Groves, D. Harame, J. Johnson, M. Hammad, Z. He, V. Ramachandran, K. Stein, S. Si Onge, S. Subbanna, D. Wang, R. Volant, X. Wang, K. Watshon, "Advanced passive devices for enhanced integrated RF circuit performance," IEEE RF-IC Symp., pp. 341-344, 2002.

[4] T. Soorapanth, C. P. Yue, D. K. Shaeffer, T. H. Lee, and S. S Wong, IEEE RF-IC Symp., "Analysis and optimization of accumulation-mode varactor for RF ICs," Symp. on VLSI Circuits Dig., pp. 32-33, 1998.

[5] K. T. Chan, A. Chin, S. P. McAlister, C. Y. Chang, V. Liang, J. K. Chen, S. C. Chien, D. S. Duh, and W. J. Lin, "Low RF loss and noise of transmission lines on Si substrates using an improved ion implantation process," in IEEE MTT-S International Microwave Symp. Dig., vol. 2, pp. 963-966, 2003.

[6] A. Chin, K. T. Chan, H. C. Huang, C. Chen, V. Liang, J. K. Chen, S. C. Chien, S. W. Sun, D. S. Duh, W. J. Lin, C. Zhu, M.-F. Li, S. P. McAlister and D. L. Kwong, "RF Passive Devices on $\mathrm{Si}$ with Excellent Performance Close to ldeal Devices Designed by Electro-Magnetic Simulation," in International Electron Devices Meeting (IEDM) Tech. Dig., pp. $375-378,2003$.

[7] C. H. Lee, K. I. Choi, M. K. Cho, Y. H. Song, K. C. Park, and K. Kim, "A Novel SONOS Structure of $\mathrm{SiO}_{2} / \mathrm{SiN} / \mathrm{Al}_{2} \mathrm{O}_{3}$ with TaN Metal Gate for Multi-Giga Bit Flash Memeries," in International Electron Devices Meeting (IEDM) Tech. Dig., pp. 613-616, 2003.

[8] C. H. Huang, K. T. Chan, C. Y. Chen; A. Chin, G W. Huang. C. Tseng, V. Liang, J. K. Chen, and S. C. Chien, "The minimum noise figure and mechanism as scaling RF MOSFETs from 0.18 to $0.13 \mu \mathrm{m}$ technology nodes," IEEE RF-IC Symp. Dig., pp. 373-376, 2003.

[9] M.Y. Yang, C.H. Huang, A. Chin, C. Zhu, B.J. Cho, M.F. Li, and Dim-Lee Kwong, "Very high density RF MIM capacitors $\left(17 \mathrm{fF} / \mu \mathrm{m}^{2}\right)$ using high- $\mathrm{Al}_{2} \mathrm{O}_{3}$ doped $\mathrm{Ta}_{2} \mathrm{O}_{5}$ dielectrics," IEEE Microwave \& Wireless Components Lett. vol. 13, no. 10, pp. $431-433,2003$. 